\title{
Active lower limb prosthetics: a systematic review of design issues and solutions
}

\author{
Michael Windrich ${ }^{1 *}$, Martin Grimmer ${ }^{3}$, Oliver Christ ${ }^{4}$, Stephan Rinderknecht ${ }^{2}$ and Philipp Beckerle ${ }^{2}$
}

From Robotics: Science and Systems 2013 Berlin, Germany. 28-Jun-16

\section{*Correspondence:}

michael.windrich@gmx.de

${ }^{1}$ Mechanical Engineering, TU

Darmstadt, 64289 Darmstadt,

Germany

Full list of author information

is available at the end of the

article

\begin{abstract}
This paper presents a review on design issues and solutions found in active lower limb prostheses. This review is based on a systematic literature search with a methodical search strategy. The search was carried out across four major technical databases and the retrieved records were screened for their relevance. A total of 21 different active prostheses, including 8 above-knee, 9 below-knee and 4 combined knee-ankle prostheses were identified. While an active prosthesis may help to restore the functional performance of an amputee, the requirements regarding the actuation unit as well as for the control system are high and the development becomes a challenging task. Regarding mechanical design and the actuation unit high force/torque delivery, high efficiency, low size and low weight are conflicting goals. The actuation principle and variable impedance actuators are discussed. The control system is paramount for a "natural functioning" of the prosthesis. The control system has to enable locomotion and should react to the amputee's intent. For this, multi-level control approaches are reviewed.
\end{abstract}

Keywords: Active prosthesis, Powered prosthesis, Artificial limb, Development, Actuation, Control, Systematic review

\section{Background}

Bipedal locomotion is fundamental for humans. In urban environments, people walk about 6500 steps per day on average [1] at a preferred walking speed of $1.3 \mathrm{~m} / \mathrm{s}$ [2]. Yet, amputations are unavoidable due to dysvascularity (72\%), infections (8\%), trauma (7\%) and several other reasons [3]. $90 \%$ of the new amputations concern the lower extremity. $53 \%$ of patients require a transtibial amputation and $39 \%$ a transfemoral amputation [3]. As dysvascularity is related to patient age, more than half of the amputees are older than 65 years. Only one-fourth of these amputees is younger than 54 years [3].

To cope with daily life activities, lower limb amputees require an adequate technical solution. Transtibial amputees require an artificial ankle, a foot and the missing part of the shank. In addition transfemoral amputees require an artificial knee and the missing part of the thigh. For a minor group of lower limb amputees, a hip replacement is required beyond this. Depending on the mobility grade [4], a specific prosthetic module for each segment is used. 
In order to provide basic functionality for standing and walking non-elastic (SACHsolid ankle cushioned heel) feet can be used for transtibial amputees [5]. As there is no energetic support from the foot structure itself, the healthy side has to compensate for it (in unilateral amputees) [6]. Further, remaining proximal joints like the hip can compensate for missing energy injection at the ankle or the knee joint [7].

An increase in functionality is possible by using ESAR feet (energy storage and return) [5]. In those, a carbon structure works like a leaf spring that is loaded in stance phase and releases energy during push off. In addition, the possible deflection allows a more natural range of motion (RoM) for the ankle joint and by this increases gait performance [8]. Even higher RoM without elastic effects is possible using prosthetic feet with a mechanical ankle joint [9].

At individual preferred walking speeds about $0.2 \mathrm{~J} / \mathrm{kg}$ to $0.29 \mathrm{~J} / \mathrm{kg}$ of positive ankle work is required. Using ESAR feet, a mean of about $0.06-0.11 \mathrm{~J} / \mathrm{kg}$ can be generated [6]. The missing energy has to be provided by additional components that add energy. This can be performed by an actuator like a motor [10], by mechanical couplings to other joints [11] or also by using gravity effects [12].

As in walking less positive work is required at the knee, compared to the ankle joint [10], passive components can perform better for knee prosthetics. In stance phase, springs and dampers allow little flexion that is required especially for comfort after touch down [13]. In addition, dampers are used to limit knee angular velocity in the early (flexion) and in the late (extension) swing phase [14]. For passive devices the damping coefficient is fixed to a predefined value, so that an online adaptation to walking speed is not possible. On the other hand, semi-active devices can provide this functionality. Such ones are using sensors to detect speed and gait phase during the gait cycle. Magnetorheological systems (Rheo knee, Ossur) or valves (C-Leg, OttoBock) are controlled by using this information to improve prosthetic performance [15]. Similar semi-active concepts are used for prosthetic feet to adapt performance at slopes (élan foot, Endolite). Furthermore such a mechanism can provide additional RoM, which results in higher comfort.

However, due to the missing power source, passive and semi-active knee joints struggle to support the amputee in tasks like climbing stairs or slopes and standing up from sitting position. Similar to the ankle joint in walking, additional positive work is required to mimic healthy human behavior. Using the passive and semi-active devices kinematic and kinetic gait analyses show more asymmetric gait and higher oxygen consumption than in non-amputees [6]. As continuous asymmetries in gait can cause long-term sequelae $[16,17]$ further improvements in prosthetic technology are required.

From an engineering point of view the three main categories of prostheses are summarized. Passive devices perform as a fixed spring and damper and hence offer only basic functionality [18]. Semiactive prostheses are capable of altering their behaviour instantaneously by means of microprocessor technology and can consequently react to situations [19]. While they offer greater flexibility, they remain limited to generate resisting forces. Active or powered prostheses provide external power through motors and consequently they have the ability to act [20]. While they offer greater performance and greater functionality, they represent the system with the highest complexity.

Over the last years various active ankle joints, knee joints and systems combining ankle and knee were developed. A recent review lists 26 active prosthetic concepts 
which were developed in the last years [6]. Older existing reviews [21-24] do not contain recent developments.

In contrast to existing reviews, this paper presents a systematic review on recent developments in active lower limb prosthetics based on a methodical search strategy. It contains a general overview of the identified prostheses and sheds light on different design approaches for the actuation unit as well as for the control system.

\section{Review}

For this review a systematic literature search was performed with a search strategy that was created using the guideline of the Cochrane Collaboration [25]. The search strategy defines the search string, the databases as well as inclusion and exclusion criteria for the screening of the retrieved records. The focus of this review lies on design issues and common solutions found in active lower limb prostheses.

\section{Search strategy}

For the selection of the databases several search runs were performed using generic search terms such as "active knee prosthesis". The following databases were chosen based on the high number of results: IEEE Explore, ScienceDirect, Engineering Village and Web of Science. The search term was created in several iterations in order to achieve a high sensitivity. Synonyms for the words "active", "lower limb" and "prosthesis" were collected and arranged in a logical structure (see Table 1). The search was limited to journal papers and conference proceedings later than 1980. An initial screening of the retrieved literature showed a great number of publications regarding arthroplasty, which is the reconstruction of joints using implants [26]. Thus, an exclusion criterion was inserted into the search string, in order to exclude those from the search due to the focus on external lower limb prosthetics.

The search retrieved a total of 3373 publications across the four selected databases. The results were then imported into EndNote X7 and duplicate records were removed.

The remaining 2595 paper were manually screened for their relevance based on the title and abstract by using the following inclusion and exclusion criteria. These criteria were established in previous search runs. This review concentrates on active prostheses that are realized as physical prototypes. Consequently, papers presenting the development of such active lower limb prostheses are included, while papers with pure theoretical concepts that are not associated with a physical prototype are excluded. The following topics led to the exclusion of a paper: orthotics, robotics, exoskeletons as well

\section{Table 1 Final search term used for the literature search}

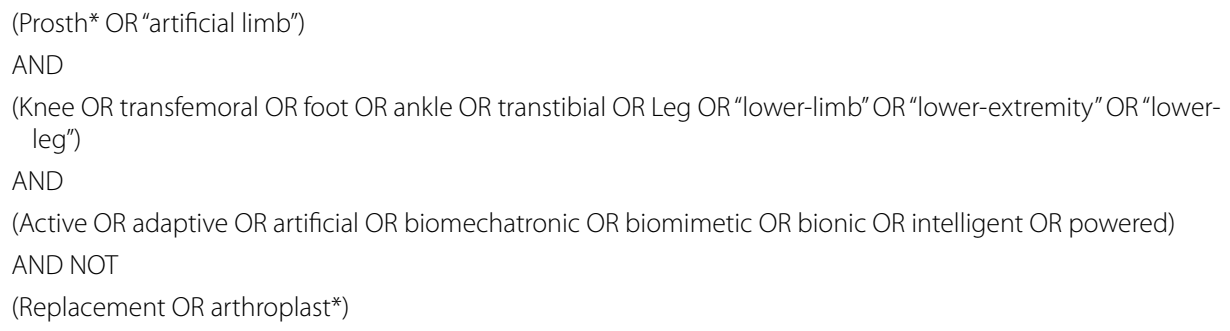


as biomechanics. Furthermore in the field of prosthetics, passive, semi-active prostheses, sockets, and other non-related medical topics as well as endoprostheses were excluded. The screening defined a total of 129 items to be relevant to this review. However, due to unobtainability and other languages, a total of 94 records are considered. The PRISMA flow diagram in Fig. 1 depicts the review process. PRISMA stands for "preferred reporting items for systematic reviews and meta-analyses" and is used in systematic reviews in order to improve reporting quality [27].

\section{Overview of active lower limb prostheses}

The literature review process identified 21 prostheses that are listed in Table 2. This discrepancy to the 26 prostheses listed in [6], arises due to the fact that neither different generations of prostheses nor commercial prostheses are taken into account for this review. Among those 21 devices are 9 below-knee, 8 above-knee and 4 combined ankle-and-knee prostheses. Each prosthesis holds different characteristics, such as the developing goal (test-bed [28], real-word application [18]), the intended purpose (lowcost prescription in developing countries [29], high-activity use for soldiers [30]), the required functional performance (force or power characteristics, supported gait modes), the degree of autonomy (tethered or self-contained [31]), the intensity of experimental testing (with able-bodied participants [32] or amputees [33]), the frequency of publication (single publication [34] or ongoing research reports [35, 36]) and the stage of development (early prototype [37] or advanced stage of development [38]).

Despite these differences, all prostheses aim at restoring the impaired functional performance of the amputee. In contrast to their passive and semi-active counterparts (see "Background" for definition), these active prostheses are capable of providing net positive work and thus "act on their own". Therefore, a control scheme that ensures a reliable interaction with the amputee [39] and enables intended motion from user commands [40] is required. Regarding actuation, conflicts of goals arise due to the requirements of the required force/torque output and high efficiency as well as low size and low weight [41]. Thus, actuation and control systems are the focused topics in the remainder of this

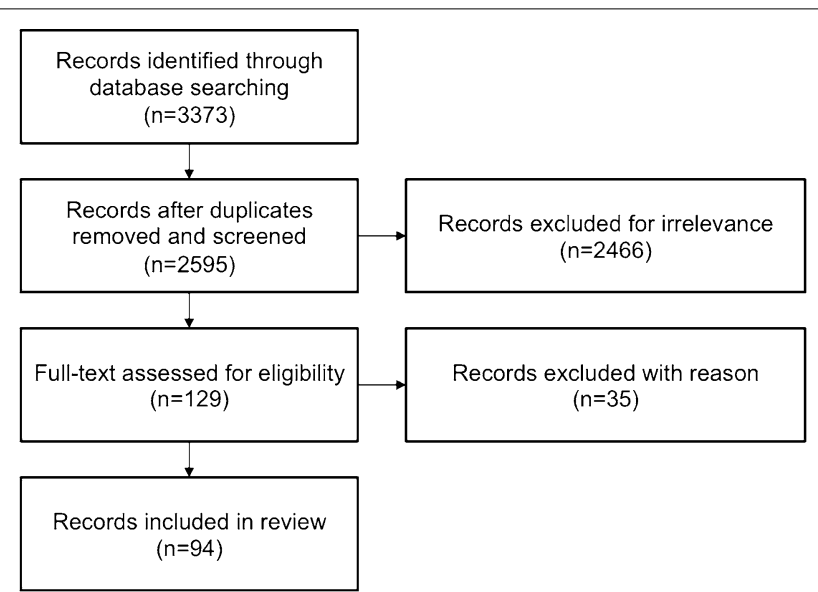

Fig. 1 PRISMA flow diagram. The literature review process is pictured throughout the different phases. In each block the number refers to the number of records 
Table 2 Overview of different prostheses

\begin{tabular}{|c|c|c|c|}
\hline Type & Name of prosthesis, Institute, Country & Year & Reference \\
\hline $\mathrm{A} / \mathrm{K}$ & $\begin{array}{l}\text { Agonist-antagonist active knee prosthesis, Massachusetts Institute of Technology, } \\
\text { USA }\end{array}$ & 2008 & [56] \\
\hline $\mathrm{A} / \mathrm{K}$ & University of Sakarya, Adapazari, Turkey & 2008 & [55] \\
\hline $\mathrm{A} / \mathrm{K}$ & Waterloo Active Prosthetic Knee, University of Waterloo, Canada & 2008 & [29] \\
\hline $\mathrm{A} / \mathrm{K}$ & Hebei University of Technology, China & 2010 & [49] \\
\hline $\mathrm{A} / \mathrm{K}$ & ETH Zurich, Switzerland & 2011 & [72] \\
\hline$A / K$ & The University of Alabama, USA & 2011 & [73] \\
\hline$A / K$ & Department of Mechanical and Aeronautical Engineering, USA & 2012 & [53] \\
\hline $\mathrm{A} / \mathrm{K}$ & University of Rhode Island, USA & 2012 & [74] \\
\hline $\mathrm{B} / \mathrm{K}$ & Bionic ankle-foot prosthesis, Massachusetts Institute of Technology, USA & 2006 & [58] \\
\hline $\mathrm{B} / \mathrm{K}$ & SPARKy, Arizona State University, USA & 2008 & [75] \\
\hline $\mathrm{B} / \mathrm{K}$ & $\begin{array}{l}\text { IPAM (intelligent Prosthesis using Artificial Muscles), Vrije Universiteit Brussel, } \\
\text { Belgium }\end{array}$ & 2008 & [28] \\
\hline $\mathrm{B} / \mathrm{K}$ & Vrije Universiteit Brussel, Belgium & 2009 & [46] \\
\hline $\mathrm{B} / \mathrm{K}$ & PANTOE 1, Peking University, China & 2010 & [57] \\
\hline $\mathrm{B} / \mathrm{K}$ & Marquette University, Milwaukee, USA & 2010 & [76] \\
\hline $\mathrm{B} / \mathrm{K}$ & Kanazawa Institute of Technology, Ishikawa, Japan & 2011 & [77] \\
\hline $\mathrm{B} / \mathrm{K}$ & AMP-foot 2.0, Vrije Universiteit Brussel, Belgium & 2012 & [78] \\
\hline $\mathrm{B} / \mathrm{K}$ & Vanderbilt Transtibial Prosthesis, Vanderbilt University, USA & 2013 & {$[32]$} \\
\hline$A / K+B / K$ & Vanderbilt Transfemoral Prosthesis, Vanderbilt University, USA & 2009 & [59] \\
\hline$A / K+B / K$ & University of Brasília, Brasil & 2009 & [79] \\
\hline$A / K+B / K$ & SmartLeg, University of Mostar, Bosnia and Herzegovina & 2011 & [34] \\
\hline$A / K+B / K$ & Cyberleg alpha, Vrije Universiteit Brussel, Belgium & 2013 & [80] \\
\hline
\end{tabular}

The prosthesis are classified as above-knee $(\mathrm{A} / \mathrm{K})$, below-knee $(\mathrm{B} / \mathrm{K})$ and combined knee-and-ankle prosthesis $(\mathrm{A} / \mathrm{K}+\mathrm{B} / \mathrm{K})$

review. Common design solutions found in prostheses are presented and discussed. The relevant literature for each topic is listed in Table 3, which can serve as a starting point for further research.

Design solutions in actuation system

The development of an active prosthesis that reaches the actuation performance of the lost limb, without exceeding its weight and size, is a big challenge [42]. The actuation unit has a great impact on these goals.

Table 3 References classified for different design solutions

\begin{tabular}{|c|c|c|}
\hline General topic & Focus & Reference \\
\hline Actuation & Electromechanical & $\begin{array}{l}{[18,19,29-31,35,37,38,41,46,49,53,55-57,62,65,75,76,78,} \\
\quad 80-102]\end{array}$ \\
\hline Actuation & Pneumatic & {$[28,42,43,54,73,103-108]$} \\
\hline Actuation & Hydraulic & {$[34]$} \\
\hline Actuation & Variable impedance actuator & $\begin{array}{l}{[18,19,28,30,31,35,38,41,46,56,57,62,65,75,76,78,80,82} \\
\quad 83,85,86,88,93,95,97,98,100]\end{array}$ \\
\hline Mechanical & Polycentric knee & {$[37,49,84,96]$} \\
\hline Control & Echo control & {$[72,109]$} \\
\hline Control & Gait mode recognition & {$[20,32,36,39,50,52,60,63,74,99,110-130]$} \\
\hline Control & EMG control & {$[40,51,53,61,69,70,115,131-141]$} \\
\hline Control & Other & {$[91,142-144]$} \\
\hline
\end{tabular}

In this table the literature was classified according to different design solutions 


\section{Actuation principle}

Applied principles are electromechanical, pneumatic and hydraulic actuation units. Electromechanical actuation is the most common principle and is used in 18 prostheses (see Table 2), even though the power density is inferior to that of a biological muscle [42]. Pneumatic actuation with pneumatic artificial muscles (PAM) is found in two prosthetic devices $[28,43]$. Supplying the required pressure to inflate the PAMs in a self-contained prosthesis is a challenging issue. An envisioned solution is to use liquid monopropellant [28], which is investigated at the University of Alabama [43, 44]. Just a single hydraulic prosthesis was found [34]. The pressure is provided by an external, portable hydraulic power supply.

\section{Variable impedance actuators}

Variable impedance actuators (VIA) create a compliant behavior of the prosthesis [45]. There are different ways to achieve the compliance, such as actuation or through integration of an elastic element into the prosthesis [45]. In the second case, a key interest is storing energy in the elastic element. This energy can be reused during gait and lower the peak force and peak power of the actuator [30]. Downsizing of the actuator, increasing the efficiency or lowering system size and weight are functional benefits [31, 46]. Moreover, through matching the impedance of the VIA with the physiological joint impedance, the prosthesis can feel more natural [31] and its behavior is more predictable to the user [35]. VIAs are far more frequent in below-knee (8 out of 9) than in aboveknee prostheses (2 out of 8 ), since gait requires significantly more net positive power in the ankle joint than in the knee [10].

\section{Knee joint mechanism}

Another design aspect found in above-knee prostheses concerns the kinematics of the knee joint. Since the human knee shows a rolling-sliding motion, the knee joint has an instantaneous center of rotation, which is defined by the centrode [47]. A so-called polycentric knee joint features a four-bar linkage, which alters the prosthesis behavior. These are primarily passive prostheses that are designed to increase stability during stance phase [48]. Just one active polycentric knee prosthesis was found in this review [49]. On the other hand Pfeifer et al. [47] conclude that a single-axis joint design is better suited for an active knee prosthesis, than a more complex polycentric mechanism.

\section{Design solutions in control system}

An important difference between semi-active and active prostheses is the inherent capability of the latter ones to act on their own by generating forces/torques. Yet, a control scheme that ensures a reliable interaction with the amputee [39] and in addition enables desired movement [40] is needed. This imposes high requirements to prosthetic control, since gait is complex and consists of different locomotive modes. A widely adopted control approach are multilevel control schemes, which allow the execution of intended movements and the transition between different locomotion patterns [40, 50]. A supervisory high-level controller monitors the movements and inputs of the amputee and generates commands related to the amputee's intent, such as the motion, which the prosthesis should perform [39]. These commands are then forwarded to an underlying 
low-level controller, which is responsible for controlling the prosthesis. Depending on the chosen high-level control strategies (see below), the controlled variables are angle/ position for echo control or force/torque for gait recognition and direct EMG control.

\section{High-level control}

High-level control is commonly separated into echo control and intent or gait mode recognition [40,51]. However, direct myoelectric control represents a different approach that has gained increasing attention in recent years.

In the case of echo control the motions of the healthy leg are recorded with sensors and then played back on the prosthetic side with a delay of a half gait cycle. In order to track the acquired angle trajectories a high mechanical impedance is required [52]. While this control scheme is relatively easy to implement, it has some major shortcomings. It cannot enable asymmetric locomotion and only applies to unilateral amputees [40]. Furthermore due to the high mechanical impedance the prosthesis feels unnatural and does not interact well with the environment [52].

The concept of intent or gait mode recognition classifies sensory user input in order to conclude the intentions or recognize the gait of the user. Based on the classification the prosthesis is set to the corresponding locomotive mode [52]. A number of sensory data can be assessed, e.g., ground reaction forces, surface electromyography (sEMG) signals, angular positions or forces applied by the amputee [39, 53]. A common underlying low-level control strategy is impedance control, where a finite-state machine is used to change the parameters of a spring and damper model [35]. This model is then converted into the impedance of the prosthesis, either by physically varying a VIA or virtually through actuation. The gait cycle is divided into individual phases and parameters for the spring and damper are defined in order to match the impedance of the prosthesis with the one of the physiological joint. This approach provides the user with more intuitive control than a rigid position control [54].

The direct EMG control or myoelectric control enables volitional control over the prosthesis based on surface EMG signals, which are obtained from electrodes in the prosthesis socket. The amputee is then capable of altering the torque by his muscle contractions [53]. Technical challenges are signal noise and high latency [50]. In addition, the amputee requires extensive training and needs to visually check the position of his leg because of the lacking proprioceptive feedback [53].

\section{Testing of active prostheses}

In this review, a large number of publications related to prosthetic research is presented and classified. Since human locomotion itself and the interaction with the amputee is very complex, prosthetic research is a time-consuming endeavour. In consequence many of the proposed concepts have never been brought past the prototyping phase [34, 5557], while other projects produced generations of refined powered prostheses [30, 35, 58].

During development, prostheses are commonly tested by a small number of amputees $[18,19,28,31,36,53,59]$ or by means of custom-made attachments through which ablebodied subjects can test them [32, 40, 42, 52, 60-63]. This aims at testing the general feasibility of different types of actuation and/or control strategies as well as iteratively 
evaluating new functions, such as additional modes of locomotion or switching between these modes.

No clinical trials that evaluate the benefits of using powered prosthesis over conventional or semi-active prosthetic prescription were found considering engineering data bases. However, some publications indicate improvements in multiple areas: These are lowered metabolic effort [38, 64, 65], increased peak ankle-power [64] and increased self-selected walking speed. [38],

Furthermore, one study with seven transtibial amputees found that subjects using powered ankle-foot prostheses experience no significant differences in metabolic energy cost, preferred walking speed, and biomechanical patterns compared to healthy subjects [38].

As all studies found in this review rely on prototypes and/or low numbers of subjects in testing, further research with clinical trials and commercial prostheses is required. The trials should not be limited to level-ground walking but also include slope and stairway ascent and descent, running as well as other gait situations of everyday life. As first powered prostheses are currently commercialized by SpringActive [66], BionX Medical Technologies [67], and Freedom Innovations [68], those can be considered in such investigations.

\section{Discussion}

Regarding actuation principles, electromechanical ones are found in most prostheses due to the beneficial power and controllability properties of DC motors. Furthermore, electromechanical actuation exhibits a practical advantage since charging from electrical outlets is convenient. While pneumatic artificial muscles (pneumatic actuation) are larger, they offer a higher force-to-weight-ratio than DC motors and intrinsically feature a compliant behavior similar to a human leg. Due to the limited maturity of monopropellants, pneumatic actuation lacks the practicability which recently prevents its application.

Many actuation concepts make use of compliant elements such as springs which can also implement variable elastic properties. These variable impedance actuators can be promising design solutions since they help to develop small but powerful prostheses that can offer more natural feel due to the compliant behaviour [31]. Differences in VIA layout can be attributed to the intended system output and use case, e.g., high maximum force for running or high efficiency for everyday-usage.

Electromechanical actuation, also in form of VIA, seems to be the most suited in terms of the requirements and appears to be the direction of development in contemporary prosthetic research and development. This conclusion is supported by the concepts that are undergoing commercialization by SpringActive, BionX, and Freedom Innovations.

A second major topic in active prosthetics and this review is the control of the devices. High-level approaches found are echo control, gait mode recognition, and direct EMG control. Echo control is a rather limited framework that does not facilitate arbitrary motions and thus appears to be less appropriate for dynamic locomotion. Currently, gait mode recognition, that adapts the impedance of the prostheses, is applied more frequent due to its higher flexibility and stability. While it is capable of supporting different locomotive modes, it remains limited to these implemented modes [40]. 
While EMG control has been investigated in upper limb prostheses for decades [69], it found only few applications in lower limb prosthetics research so far. However, a trend towards such control approaches might be assumed as roughly $80 \%$ of the included papers that are connected to EMG control were published later than 2010. The potential of EMG control is that the amputee is able to voluntarily control the flexion of the prosthesis, even though this comes with the price of a greater cognitive load [70].

In conclusion high-level controls mainly rely on gait recognition in combination with a lower level impedance control, even though indications towards voluntary, i.e. direct, EMG control exist.

\section{Conclusions}

This review informs about the state-of-the-art and recent developments in active lower limb prosthetics. In contrast to other reviews, it therefore features a systematic literature search. While first research of active prosthesis research goes back as far as the 1970's [71], it receives increasing attention since 2005 (more than 90\% of the included records). Over 21 active lower limb prostheses were identified in this systematic review.

Since a prosthesis is a mechatronic system that is designed to functionally replace a missing extremity and closely interact with the amputee, two important aspects have to be addressed during research: Actuation and control design.

While some actuator concepts rely on pneumatics, electromechanical motors are most common type and currently seem to be the most promising approach. In addition, variable impedance actuators are used-mostly in below-knee prostheses-in order to increase power output and/or increase efficiency of the systems.

Different high-level control strategies are applied so as to enable different locomotion modes and thus giving the amputee a high degree of voluntary control over the prosthesis. The most common strategies are gait mode recognition in combination with lowlevel impedance control and direct EMG control.

Three prostheses are in the process of commercialization. These concepts share the findings of this review regarding the trends in active prosthetic research, i.e., electromechanical actuation with and without variable impedance as well as sophisticated highlevel control strategies.

As of now, clinical research is limited to prototypes and low number of subjects, even though test results show the potential to restore the functional performance of an amputee in several preliminary studies. The development of active prostheses is a challenging task and thus should remain subject to future research including extended clinical evaluations.

\footnotetext{
Abbreviations

ESAR: feet energy-storage-and-return feet; PAM: pneumatic artificial muscle; RoM: range of motion; PRISMA: preferred reporting items for systematic reviews and meta-analyses; VIA: variable impedance actuator.

Authors' contributions

MW was responsible for the definition of the search strategy, carrying out the literature search and the review process. In addition he was in the lead for writing the article. MG contributed the introduction. In addition, his upcoming book chapter [6] was used to check the findings of the systematic literature search of this review. OC provided support for the methodical work and throughout the literature search. SR provided administrative work and supervision. PB was closely involved throughout the review process and for the definition of the paper structure and contents. He supported the coordination of this article and furthermore provided supervision. All authors read and approved the final manuscript.
} 


\section{Author details}

${ }^{1}$ Mechanical Engineering, TU Darmstadt, 64289 Darmstadt, Germany. ${ }^{2}$ Institute for Mechatronic Systems in Mechanical Engineering, TU Darmstadt, Otto-Berndt-Strasse 2, 64287 Darmstadt, Germany. ${ }^{3}$ Lauflabor Locomotion Laboratory, Institute of Sport Science, TU Darmstadt, Magdalenenstrasse 27,64289 Darmstadt, Germany. ${ }^{4}$ School of Applied Psychology, Institute Humans in Complex Systems, University of Applied Sciences and Arts Northwestern Switzerland, Riggenbachstrasse 16, 4600 Olten, Switzerland.

\section{Acknowledgements}

Not applicable.

Competing interests

The authors declare that they have no competing interests.

\section{Availability of data and materials}

All data generated or analysed during this study are included in this published article (and its supplementary information files).

\section{Declarations}

This article has been published as part of BioMedical Engineering OnLine Vol 15 Suppl 3, 2016: Towards Active Lower Limb Prosthetic Systems: Design Issues and Solutions. The full contents of the supplement are available online at http:// biomedical-engineering-online.biomedcentral.com/articles/supplements/volume-15-supplement-3.

\section{Funding}

This work is not based on any third party funding. The publication costs of this paper are covered from internal funds of the contributing institutions.

\section{Published: 19 December 2016}

\section{References}

1. Tudor-Locke C, Bassett DRJ. How many steps/day are enough? Preliminary pedometer indices for public health. Sports Med. 2004;34:1-8.

2. Dal U, Erdogan T, Resitoglu B, Beydagi H. Determination of preferred walking speed on treadmill may lead to high oxygen cost on treadmill walking. Gait Posture. 2010;31:366-9.

3. The Amputee Statistical Database for the United Kingdom 2006/07. http://www.limbless-statistics.org/documents/Report2006-07.pdf. Accessed 20 Nov 2013.

4. Home-Otto Bock. http://www.ottobock.com/cps/rde/xchg/ob_com_en/hs.xsl/603.html. Accessed 13 Dec 2013.

5. Gitter A, Czerniecki JM, Degroot DM. Biomechanical analysis of the influence of prosthetic feet on below-knee amputee walking. Am J Phys Med Rehabil. 1991;70:142-8.

6. Grimmer M, Seyfarth A. Mimicking human-like leg function in prosthetic limbs. In: Neuro-robotics: from brain machine interfaces to rehabilitation robotics. Berlin: Springer; 2014.

7. Winter DA, Sienko SE. Biomechanics of below-knee amputee gait. J Biomech. 1988;21:361-7.

8. Schneider K, Hart TT, Zernicke RF, Setoguchi Y, Oppenheim W. Dynamics of below-knee child amputee gait: SACH foot versus Flex foot. J Biomech. 1993;26:1191-204.

9. Postema K, Hermens HJ, DeVries J, Koopman H, Eisma WH. Energy storage and release of prosthetic feet. 1. Biomechanical analysis related to user benefits. Prosthet Orthot Int. 1997;21:17-27.

10. Grimmer M, Eslamy M, Seyfarth A. Energetic and peak power advantages of series elastic actuators in an actuated prosthetic leg for walking and running. Actuators. 2014;3:1-19.

11. Unal R, Carloni R, Behrens SM, Hekman EEG, Stramigioli S, Koopman HFJM. Towards a fully passive transfemoral prosthesis for normal walking. In: 2012 4th IEEE RAS EMBS int conf on biomed robot biomechatronics BioRob. New York: IEEE; 2012.

12. Collins SH, Kuo AD. Recycling energy to restore impaired ankle function during human walking. PLoS ONE. 2010;5:e9307.

13. Kampas P. Technologie und Funktionsweise des Genium-Prothesenkniegelenks. Orthop Tech. 2011;62:898

14. Segal AD, Orendurff MS, Klute GK, McDowell ML, Pecoraro JA, Shofer J, Czerniecki JM. Kinematic and kinetic comparisons of transfemoral amputee gait using C-Leg and Mauch SNS prosthetic knees. J Rehabil Res Dev. 2006;43:857-70.

15. Blumentritt S. Prothetik. Zur Biomechanik des mikroprozessorgesteuerten Prothesenkniegelenks Genium. Orthop Tech. 2012;63:24.

16. Robbins CB, Vreeman DJ, Sothmann MS, Wilson SL, Oldridge NB. A review of the long-term health outcomes associated with war-related amputation. Mil Med. 2009;174:588-92.

17. Gailey R, Allen K, Castles J, Kucharik J, Roeder M. Review of secondary physical conditions associated with lowerlimb amputation and long-term prosthesis use. J Rehabil Res Dev. 2008:45:15-30.

18. Au S, Berniker M, Herr H. Powered ankle-foot prosthesis to assist level-ground and stair-descent gaits. Neural Netw. 2008:21:654-66

19. Martinez-Vilialpando EC, Herr H. Agonist-antagonist active knee prosthesis: a preliminary study in level-ground walking. J Rehabil Res Dev. 2009:46:361-73. 
20. Varol HA, Goldfarb M. Decomposition-based control for a powered knee and ankle transfemoral prosthesis. In: 2007 IEEE 10th international conference on rehabilitation robotics, ICORR'07. New York: Inst. of Elec. and Elec. Eng. Computer Society; 2007. p. 783-9.

21. Bogue R. Exoskeletons and robotic prosthetics: a review of recent developments. Ind Robot Int J. 2009;36:6.

22. Collins DM, Karmarkar A, Relich R, Pasquina PF, Cooper RA. Review of research on prosthetic devices for lower extremity amputation. Crit Rev Biomed Eng. 2006;34:379-438.

23. Torrealba RR, Fernández-López G, Grieco JC. Towards the development of knee prostheses: review of current researches. Kybernetes. 2008;37(9/10):1561-76.

24. Versluys R, Desomer A, Lenaerts G, Beyl P, Van Damme M, Vanderborght B, Vanderniepen I, Van der Perre G, Lefeber D. From conventional prosthetic feet to bionic feet: a review study. In: 2008 2nd IEEE RAS EMBS international conference on biomedical robotics and biomechatronics. New York: IEEE; 2008. p. 49-54.

25. How to develop a search strategy for a cochrane review. http://chmg.cochrane.org/sites/chmg.cochrane.org/files/ uploads/How\%20to\%20develop\%20a\%20search\%20strategy-support-manual.pdf. Accessed 12 Nov 2013.

26. Palmer SH, Cross MJ. Total knee arthroplasty. 2014.

27. Moher D, Liberati A, Tetzlaff J, Altman DG. The PRISMA group: preferred reporting items for systematic reviews and meta-analyses: the PRISMA statement. PLoS Med. 2009;6:e1000097.

28. Versluys R, Desomer A, Lenaerts G, Van Damme M, Beyl P, Van Der Perre G, Peeraer L, Lefeber D. A pneumatically powered below-knee prosthesis: design specifications and first experiments with an amputee. In: Proceedings of the 2nd biennial IEEE/RAS-EMBS international conference on biomedical robotics and biomechatronics, BioRob 2008. New York: Inst. of Elec. and Elec. Eng. Computer Society; 2008. p. 372-7.

29. Borjian R, Lim J, Khamesee MB, Melek W. The design of an intelligent mechanical active prosthetic knee. In: Proceedings - 34th annual conference of the IEEE industrial electronics society, IECON 2008. New York: Inst. of Elec. and Elec. Eng. Computer Society; 2008. p. 3016-21.

30. Holgate MA, Hitt JK, Bellman RD, Sugar TG, Hollander KW. The SPARKy (spring ankle with regenerative kinetics) project: choosing a DC motor based actuation method. In: Proceedings of the 2nd biennial IEEE/RAS-EMBS international conference on biomedical robotics and biomechatronics, BioRob 2008. New York: Inst. of Elec. and Elec. Eng. Computer Society; 2008. p. 163-8.

31. Cherelle P, Grosu V, Matthys A, Vanderborght B, Lefeber D. Design and validation of the ankle mimicking prosthetic (AMP-) foot 2.0. IEEE Trans Neural Syst Rehabil Eng. 2013.

32. Shultz AH, Mitchell JE, Truex D, Lawson BE, Goldfarb M. Preliminary evaluation of a walking controller for a powered ankle prosthesis. In: Proceedings-IEEE international conference on robotics and automation. New York: Institute of Electrical and Electronics Engineers Inc:; 2013. p. 4837-43.

33. Martinez-Villalpando EC, Mooney L, Elliott G, Herr H. Antagonistic active knee prosthesis. A metabolic cost of walking comparison with a variable-damping prosthetic knee. In: Proceedings of the annual international conference of the IEEE engineering in medicine and biology society, EMBS. New York: Institute of Electrical and Electronics Engineers Inc;; 2011. p. 8519-22.

34. Dedic R, Dindo H. SmartLeg: An intelligent active robotic prosthesis for lower-limb amputees. In: 2011 23rd international symposium on information, communication and automation technologies, ICAT 2011. bhT; m:tel-imate prijatelije; ENERGOINVEST-SUI-Sistemi upravljanja energijom; Microsoft. New York: IEEE Computer Society; 2011.

35. Sup F, Varol HA, Mitchell J, Withrow T, Goldfarb M. Design and control of an active electrical knee and ankle prosthesis. In: Proceedings of the 2nd biennial IEEE/RAS-EMBS international conference on biomedical robotics and biomechatronics, BioRob 2008. New York: Inst. of Elec. and Elec. Eng. Computer Society; 2008. p. 523-8.

36. Lawson BE, Varol HA, Huff A, Erdemir E, Goldfarb M. Control of stair ascent and descent with a powered transfemoral prosthesis. IEEE Trans Neural Syst Rehabil Eng. 2013;21:466-73.

37. Geng Y, Yang P, Xu X, Chen L. Design and simulation of active transfemoral prosthesis. In: Proceedings of the 2012 24th Chinese control and decision conference, CCDC 2012. New York: IEEE Computer Society; 2012. p. 3724-28.

38. Herr HM, Grabowski AM. Bionic ankle-foot prosthesis normalizes walking gait for persons with leg amputation. Proc R Soc B Biol Sci. 2012;279:457-64.

39. Varol HA, Sup F, Goldfarb M. Real-time gait mode intent recognition of a powered knee and ankle prosthesis for standing and walking. In: Proceedings of the 2nd biennial IEEE/RAS-EMBS international conference on biomedical robotics and biomechatronics, BioRob 2008. New York: Inst. of Elec. and Elec. Eng. Computer Society; 2008. p. 66-72.

40. Wu SK, Waycaster G, Shen XR. Electromyography-based control of active above-knee prostheses. Control Eng Pract. 2011;19:875-82.

41. Au SK, Herr HM. Powered ankle-foot prosthesis-the importance of series and parallel motor elasticity. IEEE Robot Autom Mag. 2008;15:52-9.

42. Sup F, Bohara A, Goldfarb M. Design and control of a powered transfemoral prosthesis. Int J Robot Res, 2008;27:263-73.

43. Waycaster G, Wu SK, Shen XR. Design and control of a pneumatic artificial muscle actuated above-knee prosthesis. J Med Devices. 2011:5:031003.

44. Shen X, Christ D. Design and control of chemomuscle: a liquid-propellant-powered muscle actuation system. J Dyn Syst Meas Control. 2011;133:021006.

45. Vanderborght B, Albu-Schaeffer A, Bicchi A, Burdet E, Caldwell DG, Carloni R, Catalano M, Eiberger O, Friedl W, Ganesh G, Garabini M, Grebenstein M, Grioli G, Haddadin S, Hoppner H, Jafari A, Laffranchi M, Lefeber D, Petit F, Stramigioli S, Tsagarakis N, Van Damme M, Van Ham R, Visser LC, Wolf S. Variable impedance actuators: a review. Robot Auton Syst. 2013;61:1601-14.

46. Versluys R, Matthys A, Van Ham R, Vanderniepen I, Lefeber D. Powered ankle-foot system that mimics intact human ankle behavior: proposal of a new concept. In: 2009 IEEE international conference on rehabilitation robotics, ICORR 2009. New York: IEEE Computer Society; 2009. p. 658-62. 
47. Pfeifer S, Riener R, Vallery H. An actuated transfemoral prosthesis with optimized polycentric knee joint. In: Proceedings of the IEEE RAS and EMBS international conference on biomedical robotics and biomechatronics. New York: IEEE Computer Society; 2012. p. 1807-12.

48. Gard SA. The influence of four-bar linkage knees on prosthetic swing-phase floor clearance. J Prosthet Orthot. 1996;8:34-40

49. Geng $Y, X u X, C h e n L$, Yang P. Design and analysis of active transfemoral prosthesis. In: IECON proceedings (industrial electronics conference). New York: IEEE Computer Society; 2010. p. 1495-99.

50. Varol HA, Sup F, Goldfarb M. Multiclass real-time intent recognition of a powered lower limb prosthesis. IEEE Trans Biomed Eng. 2010;57:542-51.

51. Hoover CD, Fite KB, Fulk GD, Holmes DW. Myoelectric torque control of an active transfemoral prosthesis during stair ascent, vol 2. In: ASME 2011 dynamic systems and control conference and Bath/ASME symposium on fluid power and motion control, DSCC 2011. New York: American Society of Mechanical Engineers; 2011. p. 451-58.

52. Varol HA, Goldfarb M: Real-time intent recognition for a powered knee and ankle transfemoral prosthesis. In: 2007 IEEE 10th international conference on rehabilitation robotics, ICORR'07. New York: Inst. of Elec. and Elec. Eng. Computer Society; 2007. p. 16-23.

53. Hoover CD, Fulk GD, Fite KB. The design and initial experimental validation of an active myoelectric transfemoral prosthesis. J Med Devices. 2012;6:011005.

54. Sup F, Bohara A, Goldfarb M. Design and control of a powered knee and ankle prosthesis. In: Proceedings—IEEE international conference on robotics and automation. New York: Institute of Electrical and Electronics Engineers Inc.; 2007. p. 4134-9.

55. Kapti AO, Yucenur MS. Design and control of an active artificial knee joint. Mech Mach Theory. 2006;41:1477-85.

56. Martinez-Villalpando EC, Weber J, Elliott G, Herr H. Design of an agonist-antagonist active knee prosthesis. In: Proceedings of the 2nd biennial IEEE/RAS-EMBS international conference on biomedical robotics and biomechatronics, BioRob 2008. New York: Inst. of Elec. and Elec. Eng. Computer Society; 2008. p. 529-34.

57. Zhu J, Wang Q, Wang L. PANTOE 1: Biomechanical design of powered ankle-foot prosthesis with compliant joints and segmented foot. In: IEEE/ASME international conference on advanced intelligent mechatronics, AIM. New York: Institute of Electrical and Electronics Engineers Inc.; 2010. p. 31-6.

58. Au SK, Dilworth P, Herr H. An ankle-foot emulation system for the study of human walking biomechanics, vol 2006. In: Proceedings -IEEE international conference on robotics and automation. New York: Institute of Electrical and Electronics Engineers Inc.; 2006. p. 2939-45.

59. Sup F, Varol HA, Mitchell J, Withrow TJ, Goldfarb M. Self-contained powered knee and ankle prosthesis: initial evaluation on a transfemoral amputee. In: 2009 IEEE international conference on rehabilitation robotics, ICORR 2009. New York: IEEE Computer Society; 2009. p. 638-44.

60. Lawson BE, Shultz AH, Goldfarb M. Evaluation of a coordinated control system for a pair of powered transfemoral prostheses. In: Proceedings_-IEEE international conference on robotics and automation. New York: Institute of Electrical and Electronics Engineers Inc.; 2013. p. 3888-93.

61. Wu S-K, Waycaster G, Shen X. Active knee prosthesis control with electromyography, vol 1. In: ASME 2010 dynamic systems and control conference, DSCC2010. New York: American Society of Mechanical Engineers; 2010. p. 785-91.

62. Fite K, Mitchell J, Sup F, Goldfarb M. Design and control of an electrically powered knee prosthesis. In: 2007 IEEE 10th international conference on rehabilitation robotics, ICORR'07. New York: Inst. of Elec. and Elec. Eng. Computer Society; 2007. p. 902-5.

63. Zhang F, Liu M, Huang H. Preliminary study of the effect of user intent recognition errors on volitional control of powered lower limb prostheses. In: Proceedings of the annual international conference of the IEEE engineering in medicine and biology society, EMBS. New York: Institute of Electrical and Electronics Engineers Inc.; 2012. p. 2768-71.

64. Mancinelli C, Patritti BL, Tropea P, Greenwald RM, Casler R, Herr H, Bonato P. Comparing a passive-elastic and a powered prosthesis in transtibial amputees. In: Proceedings of the annual international conference of the IEEE engineering in medicine and biology society, EMBS. New York: Institute of Electrical and Electronics Engineers Inc.; 2011:8255-8.

65. Au SK, Herr H, Weber J, Martinez-Villalpando EC. Powered ankle-foot prosthesis for the improvement of amputee ambulation. In: Annual international conference of the IEEE engineering in medicine and biology — proceedings. New York: Inst. of Elec. and Elec. Eng. Computer Society; 2007. p. 3020-26.

66. SpringActive. http://www.springactive.com. Accessed 18 Jan 2014.

67. Home-BionX medical technologies. http://www.bionxmed.com. Accessed 21 Jan 2014

68. Freedom innovations: lower extremities prosthetics. http://www.freedom-innovations.com/freedom-innovationsto-commercialize-the-worlds-first-actively-powered-complete-lower-extremity-prosthesis. Accessed 21 Jan 2014.

69. Hargrove LJ, Simon AM, Lipschutz R, Finucane SB, Kuiken TA. Non-weight-bearing neural control of a powered transfemoral prosthesis. J Neuroeng Rehabil. 2013;10:1.

70. Hoover CD, Fulk GD, Fite KB. Stair ascent with a powered transfemoral prosthesis under direct myoelectric control. IEEE-ASME Trans Mechatron. 2013;18:1191-200.

71. Grimes DL, Flowers WC, Donath M. Feasibility of an active control scheme for above knee prostheses. J Biomech Eng. 1977;99:215-21.

72. Vallery H, Burgkart R, Hartmann C, Mitternacht J, Riener R, Buss M. Complementary limb motion estimation for the control of active knee prostheses. Biomed Tech. 2011;56:45-51.

73. Waycaster G, Wu S-K, Shen X. A pneumatic artificial muscle actuated above-knee prosthesis, vol 1. In: ASME 2010 dynamic systems and control conference, DSCC2010. New York: American Society of Mechanical Engineers; 2010. p. $793-800$.

74. Du L, Zhang F, Liu M, Huang H. Toward design of an environment-aware adaptive locomotion-mode-recognition system. IEEE Trans Biomed Eng. 2012;59:2716-25. 
75. Hitt JK, Bellman R, Holgate M, Sugar TG, Hollander KW. The sparky (spring ankle with regenerative kinetics) project: design and analysis of a robotic transtibial prosthesis with regenerative kinetics, vol 5 PART C. In: 2007 Proceedings of the ASME international design engineering technical conferences and computers and information in engineering conference, DETC2007, New York: American Society of Mechanical Engineers; 2008. p. 1587-96.

76. Bergelin BJ, Mattos JO, Wells JG, Voglewede PA. Concept through preliminary bench testing of a powered lower limb prosthetic device. J Mech Robot. 2010;2:041005.

77. Suzuki R, Sawada T, Kobayashi N, Hofer EP. Control method for powered ankle prosthesis via internal model control design. In: 2011 IEEE international conference on mechatronics and automation, ICMA 2011. New York: IEEE Computer Society; 2011. p. 237-42.

78. Cherelle P, Matthys A, Grosu V, Vanderborght B, Lefeber D. The AMP-foot 2.0: mimicking intact ankle behavior with a powered transtibial prosthesis. In: Proceedings of the IEEE RAS and EMBS international conference on biomedical robotics and biomechatronics. New York: IEEE Computer Society; 2012. p. 544-9.

79. Delis AL, Carvalho JLA, da Rocha AF, Ferreira RU, Rodrigues SS, Borges GA. Estimation of the knee joint angle from surface electromyographic signals for active control of leg prostheses. Physiol Meas. 2009;30:931-46.

80. Geeroms J, Flynn L, Jimenez-Fabian R, Vanderborght B, Lefeber D. Ankle-knee prosthesis with powered ankle and energy transfer for CYBERLEGs-prototype. In: IEEE int conf on rehabil robot ICORR 2013. New York: IEEE. 2013.

81. Ming $L$, Datseris $P, H e H$. A prototype for smart prosthetic legs-analysis and mechanical design. Adv Mater Res. 2011:403-408:1999-2006.

82. Sugar TG, Hollander KW, Hitt JK. Walking with springs. In: Proc SPIE—int soc opt Eng. Bellingham: International Society for Optics and Photonics; 2011. p. 797602.

83. Wentink EC, Koopman HFJM, Stramigioli S, Rietman JS, Veltink PH. Variable stiffness actuated prosthetic knee to restore knee buckling during stance: a modeling study. 2012

84. Kim Ki J, Wu C, Wang F, Wen S. The research of the four-bar bionic active knee. Adv Mater Res. 2011:308-310:1988-91.

85. Bellman RD, Holgate MA, Sugar TG. SPARKy 3: design of an active robotic ankle prosthesis with two actuated degrees of freedom using regenerative kinetics. In: Proceedings of the 2nd biennial IEEE/RAS-EMBS international conference on biomedical robotics and biomechatronics, BioRob 2008. NEw York: Inst. of Elec. and Elec. Eng. Computer Society; 2008. p. 511-6.

86. Hitt J, Sugar T, Holgate M, Bellman R, Hollander K. Robotic transtibial prosthesis with biomechanical energy regeneration. Ind Robot Int J. 2009;36:441-7.

87. Liu M, Datseris P, Huang H. Prototype for smart prosthetic legs-analysis and mechanical design, vol 403-408. In: Advanced Materials Research. Zurich: Trans Tech Publications; 2012. p. 1999-2006.

88. Au SK, Weber J, Herr H. Powered ankle-foot prosthesis improves walking metabolic economy. IEEE Trans Robot. 2009;25:51-66.

89. Tucker MR, Fite KB. Mechanical damping with electrical regeneration for a powered transfemoral prosthesis. In: IEEE/ASME international conference on advanced intelligent mechatronics, AIM. New York: Institute of Electrical and Electronics Engineers Inc.; 2010. p. 13-8.

90. Powelson T, Yang J. Finite element analysis of piezoelectric strips for modifying ankle torques in active prosthetic feet—a pilot study, vol 4. In: Proceedings of the ASME design engineering technical conference. New York: American Society of Mechanical Engineers; 2012. p. 133-41.

91. Andrade JAA, Silva RC, Brasil LM, Rosa SF. Development of an active prosthesis for transtibial amputees. In: 2011 Pan Health Care Exch PAHCE Am. New York: IEEE. 2011.

92. Hoover CD, Fite KB. Development of a powered-knee transfemoral prosthesis prototype. In: ASME 2011 summer bioengineering conference, SBC 2011. New York: American Society of Mechanical Engineers; 2011. p. 531-2.

93. Bergelin BJ, Voglewede PA. Design of an active ankle-foot prosthesis utilizing a four-bar mechanism. J Mech Des. 2012:134:061004.

94. Wells Jr JG, Voglewede PA, Rocheleau DM. Design for improved trans-tibial prosthetic devices using four bar mechanisms, vol 7A. In: Proceedings of the ASME international design engineering technical conferences and computers and information in engineering conference-DETC2005. New York: American Society of Mechanical Engineers; 2005. p. 467-73.

95. Han Y, Jia S, Wang X. Design and simulation of an ankle prosthesis with lower power based on human biomechanics. Robot. 2013;35:276-82.

96. Kim Ki J, Wu C, Wang F, Wen S. By the ball screw drive a new initiative knee joint structure design. Appl Mech Mater. 2011;58-60:332-7.

97. Martinez-Villalpando EC, Weber J, Elliott G, Herr H. Biomimetic prosthetic knee using antagonistic muscle-like activation, vol 2. In: ASME international mechanical engineering congress and exposition, proceedings. New York: American Society of Mechanical Engineers; 2009. p. 141-3.

98. Au SK, Weber J, Herr H. Biomechanical design of a powered ankle-foot prosthesis. In: 2007 IEEE 10th international conference on rehabilitation robotics, ICORR'07. New York: Inst. of Elec. and Elec. Eng. Computer Society; 2007. p. 298-303.

99. Yang P, Chen L, Guo X, Wang X, Li L. Artificial lower limb with myoelectrical control based on support vector machine, vol 2. In: Proceedings of the world congress on intelligent control and automation (WCICA). New York: Institute of Electrical and Electronics Engineers Inc.; 2006. p. 9486-89.

100. Hitt JK, Sugar TG, Holgate M, Bellman R. An active foot-ankle prosthesis with biomechanical energy regeneration. J Med Devices. 2010;4:011003.

101. Mattos JO, Kane ED, Voglewede PA. Active component lower limb prosthetic device research: concept and design, vol 8 Part A. In: 2007 Proceedings of the ASME international design engineering technical conferences and computers and information in engineering conference, DETC2007. New York: American Society of Mechanical Engineers; 2008. p. 607-13. 
102. Wang F, Zhang Y, Ye T, Wu C. A hybrid actuation scheme of trans-femoral prosthesis for motion adaptation. In: 2009 4th IEEE conference on industrial electronics and applications, ICIEA 2009. New York: IEEE Computer Society; 2009. p. 2850-54.

103. Versluys R, Desomer A, Lenaerts G, Van Ham R, Vanderniepen I, Peeraer L, Lefeber D. On the development of a powered prosthesis for transtibial amputees, vol 22 IFMBE. In: IFMBE Proceedings. Berlin: Springer; 2008. p. 1612-5.

104. Sup FC, Goldfarb M. Design of a pneumatically actuated transfemoral prosthesis. In: American society of mechanical engineers, dynamic systems and control division (Publication) DSC. New York: American Society of Mechanical Engineers; 2006

105. Shen XR, Waycaster G, Wu SK. Design and control of a variable-radius pulley-based pneumatic artificial muscle actuation system. Int J Robot Autom. 2013;28:389-400.

106. Dabiri Y, Najarian S, Eslami MR, Zahedi S, Moser D. A powered prosthetic knee joint inspired from musculoskeletal system. Biocybern Biomed Eng. 2013;33:118-24.

107. Driver T, Wu S-K, Shen X. A pneumatic muscle-actuated transfemoral prosthesis. In: ASME 20125 th annu dyn syst control conf JT JSME 201211 th motion vib conf DSCC 2012-MOVIC 2012. New York: American Society of Mechanical Engineers; 2012. p. 779-86.

108. Versluys R, Desomer A, Lenaerts G, Pareit O, Vanderborght B, Peeraer L, Lefeber D. A biomechatronical transtibial prosthesis powered by pleated pneumatic artificial muscles. Int J Model Identif Control. 2008;4:394-405.

109. Borjian R, Khamesee MB, Melek W. Feasibility study on echo control of a prosthetic knee: sensors and wireless communication. Microsyst Technol. 2010;16:257-65.

110. Gou B, Liu Z, Zhao L, Yang P. Walking mode pre-judgment of lower limb prosthesis based on correlation analysis. J Southeast Univ Nat Sci Ed. 2013;43(SUPPL.I):192-6.

111. Wang $\mathrm{D}, \mathrm{Du} \mathrm{L}$, Huang $\mathrm{H}$. Terrain recognition improves the performance of neural-machine interface for locomotion mode recognition. In: 2013 international conference on computing, networking and communications, ICNC 2013. New York: IEEE Computer Society; 2013. p. 87-91.

112. Lawson BE, Varol HA, Sup F, Goldfarb M. Stumble detection and classification for an intelligent transfemoral prosthesis. In: 2010 annual international conference of the IEEE engineering in medicine and biology society, EMBC'10. New York: IEEE Computer Society; 2010. p. 511-4.

113. Yanli G, Peng Y, Lingling C. Study of the control of active transfemoral prosthesis based on CPG. Adv Mater Res. 2012:468-471:1710-3.

114. Lawson BE, Varol HA, Goldfarb M. Standing stability enhancement with an intelligent powered transfemoral prosthesis. IEEE Trans Biomed Eng. 2011;58:2617-24.

115. Zhang $\mathrm{F}$, Huang $\mathrm{H}$. Source selection for real-time user intent recognition toward volitional control of artificial legs. IEEE J Biomed Health Inform. 2013:17:907-14

116. Zhang F, Dou Z, Nunnery M, Huang H. Real-time implementation of an intent recognition system for artificial legs. In: Proceedings of the annual international conference of the IEEE engineering in medicine and biology society, EMBS. New York: Institute of Electrical and Electronics Engineers Inc.; 2011. p. 2997-3000.

117. Varol HA, Sup F, Goldfarb M. Powered sit-to-stand and assistive stand-to-sit framework for a powered transfemoral prosthesis. In: 2009 IEEE international conference on rehabilitation robotics, ICORR 2009. New York: IEEE Computer Society; 2009. p. 645-51

118. Liu L, Yang P, Liu Z, Chen L, Geng Y. Pattern recognition of the thigh amputee motion based on genetic algorithm and BP, vol 254 LNEE. In: Lecture notes in electrical engineering. Berlin: Springer; 2013. p. 291-8.

119. Zheng E, Wang L, Luo Y, Wei K, Wang Q. Non-contact capacitance sensing for continuous locomotion mode recognition: design specifications and experiments with an amputee. In: IEEE int conf on rehabil robot ICORR 2013. New York: IEEE; 2013

120. Tkach DC, Hargrove $\sqcup$. Neuromechanical sensor fusion yields highest accuracies in predicting ambulation mode transitions for trans-tibial amputees. In: Proceedings of the annual international conference of the IEEE engineering in medicine and biology society, EMBS. New York: Institute of Electrical and Electronics Engineers Inc.; 2013. p. 3074-77.

121. Miller JD, Beazer MS, Hahn ME. Myoelectric walking mode classification for transtibial amputees. IEEE Trans Biomed Eng. 2013;60:2745-50.

122. Tkach DC, Lipschutz RD, Finucane SB, Hargrove LJ. Myoelectric neural interface enables accurate control of a virtual multiple degree-of-freedom foot-ankle prosthesis. In: IEEE int conf on rehabil robot ICORR 2013. New York: IEEE. 2013.

123. Chen BJ, Zheng EH, Fan XD, Liang T, Wang QN, Wei KL, Wang L. Locomotion mode classification using a wearable capacitive sensing system. IEEE Trans Neural Syst Rehabil Eng. 2013:21:744-55.

124. Liu L, Yang P, Liu Z, Geng Y, Zhang J. Leg amputees motion pattern recognition based on principal component analysis and BP network. In: 2013 25th Chinese control and decision conference, CCDC 2013. New York: IEEE Computer Society; 2013. p. 3802-4.

125. Lawson BE, Varol HA, Goldfarb M. Ground adaptive standing controller for a powered transfemoral prosthesis. In: IEEE international conference on rehabilitation robotics. New York: IEEE Computer Society; 2011.

126. Huang H, Zhang F, Sun YL, He HB. Design of a robust EMG sensing interface for pattern classification. J Neural Eng. 2010;7:056005.

127. Young AJ, Simon A, Hargrove LJ. An intent recognition strategy for transfemoral amputee ambulation across different locomotion modes. In: Proceedings of the annual international conference of the IEEE engineering in medicine and biology society, EMBS. New York: Institute of Electrical and Electronics Engineers Inc.; 2013. p. 1587-90.

128. Chen L, Yang P, Xu X, Zu L, Guo X. Above-knee prosthesis control based on posture recognition by support vector machine. In: 2008 IEEE International Conference on Robotics, Automation and Mechatronics, RAM 2008. New York: Inst. of Elec. and Elec. Eng. Computer Society; 2008. p. 307-12.

129. Zheng E, Chen B, Wang Q, Wei K, Wang L. A wearable capacitive sensing system with phase-dependent classifier for locomotion mode recognition. In: Proceedings of the IEEE RAS and EMBS international conference on biomedical robotics and biomechatronics. New York: IEEE Computer Society; 2012. p. 1747-52. 
130. Huff AM, Lawson BE, Goldfarb M. A running controller for a powered transfemoral prosthesis. In: Proceedings of the annual international conference of the IEEE engineering in medicine and biology society, EMBS. New York: Institute of Electrical and Electronics Engineers Inc.; 2012. p. 4168-71.

131. Ha KH, Varol HA, Goldfarb M. Volitional control of a prosthetic knee using surface electromyography. IEEE Trans Biomed Eng. 2011;58:144-51.

132. Chen L, Yang P, Geng Y, Liu Z: Torque recognition of knee joint based on electromyography. Zhongnan Daxue Xuebao Ziran Kexue Ban J Cent South Univ Sci Technol 2013, 44(SUPPL.2):117-121.

133. Guo X, Yang P, Chen L, Wang X, Li L. Study of the control mechanism of robot-prosthesis based-on the EMG processed, vol 2. In: Proceedings of the world congress on intelligent control and automation (WCICA). New York: Institute of Electrical and Electronics Engineers Inc.; 2006. p. 9490-3.

134. Wang J, Kannape OA, Herr HM. Proportional EMG control of ankle plantar flexion in a powered transtibial prosthesis. In: IEEE int conf on rehabil robot ICORR 2013. New York: IEEE; 2013.

135. Hoover CD, Fite KB. Preliminary evaluation of myoelectric control of an active transfemoral prosthesis during stair ascent, vol 1. In: ASME 2010 dynamic systems and control conference, DSCC2010. New York: American Society of Mechanical Engineers; 2010. p. 801-8.

136. Ha KH, Varol HA, Goldfarb M. Myoelectric control of a powered knee prosthesis for volitional movement during non-weight-bearing activities. In: 2010 annual international conference of the IEEE engineering in medicine and biology society, EMBC'10. New York: IEEE Computer Society; 2010. p. 3515-8.

137. Du L, Zhang F, He H, Huang H. Improving the performance of a neural-machine interface for prosthetic legs using adaptive pattern classifiers. In: Proceedings of the annual international conference of the IEEE engineering in medicine and biology society, EMBS. New York: Institute of Electrical and Electronics Engineers Inc.; 2013. p. $1571-4$.

138. Dawley JA, Fite KB, Fulk GD. EMG control of a bionic knee prosthesis: exploiting muscle co-contractions for improved locomotor function. In: IEEE int conf on rehabil robot ICORR 2013. New York: IEEE; 2013.

139. Myers DR, Moskowitz GD. Active EMG-controlled A/K prosthesis. Oxford: Pergamon Press; 1983. p. 35-41.

140. Zhang $X$, Huang $H$, Yang Q. A special purpose embedded system for neural machine interface for artificial legs. In: 2011 annu int conf IEEE eng med biol soc. New York: IEEE. 2011.

141. Hoover CD, Fite KB: A configuration dependent muscle model for the myoelectric control of a transfemoral prosthesis. In: IEEE international conference on rehabilitation robotics. New York: IEEE Computer Society; 2011.

142. Kalanovic VD, Popovic DB. Tracking method for the control of the above-knee prosthesis. Autom Remote Control. 1993:54:119-32.

143. Fujimoto $\mathrm{H}$, Kato I. Method of controlling A/K prosthesis for ascending with disabled side hip joint torque. Trans Jpn Soc Mech Eng Part C. 1995;61:641-6.

144. Zhang F, D'Andrea SE, Nunnery MJ, Kay SM, Huang H. Towards design of a stumble detection system for artificial legs. IEEE Trans Neural Syst Rehabil Eng. 2011;19:567-77.

Submit your next manuscript to BioMed Central and we will help you at every step:

- We accept pre-submission inquiries

- Our selector tool helps you to find the most relevant journal

- We provide round the clock customer support

- Convenient online submission

- Thorough peer review

- Inclusion in PubMed and all major indexing services

- Maximum visibility for your research

Submit your manuscript at www.biomedcentral.com/submit 